\title{
Laparoscopic Management of Tubal Ectopic of Heterotopic Pregnancy
}

\author{
E SAHA $^{\mathrm{a}}, \mathrm{JDAS}^{\mathrm{b}}$, M MONIRUZZAMAN $^{\mathrm{c}}, \mathrm{CR}^{\mathrm{B}} \mathrm{BACHER}^{\mathrm{d}}$
}

\begin{abstract}
Summary:
A heterotopic pregnancy is a rare complication of pregnancy in which both extra-uterine (ectopic pregnancy) and intrauterine pregnancy occur simultaneously. The prevalence of heterotopic pregnancy is estimated at 0.6- 2.5: 10,000 pregnancy. It is a challenge for obstetrician to manage the tubal pregnancy without interruption of intrauterine pregnancy. Here we describe a case who had left tubal alive ectopic pregnancy \& also intrauterine alive pregnancy simultaneously after a natural conception. This patient was managed successfully with laparoscopic left salpingectomy, and intrauterine pregnancy has been continuing. There are
\end{abstract}

\section{Introduction:}

Heterotopic pregnancy is defined as the presence of simultaneous pregnancies in two different implantation sites. The most frequent observed manifestation is the presence of an intrauterine pregnancy and an ectopic pregnancy that is usually located in the uterine tube, most commonly in its ampullary portion $(80 \%)^{1}$. Abdominal pregnancy is a rare, can present as extra uterine portion of heterotopic pregnancy ${ }^{2}$. Cornual pregnancy was also reported. The prevalence of heterotopic pregnancy is estimated at $0.6-2.5: 10,000$ pregnancy $^{3}$. The incidence of heterotopic pregnancy is around 1/30,000 in spontaneous pregnancy. This is an increasingly common complication of assisted reproductive technology. The incidence of those cases are greater ranging from $1 / 100$ to $1 / 3,600^{4,5}$.

Here we describe a case of heterotopic pregnancy during first trimester who had left tubal alive ectopic

a. Dr Eti Saha, Assistant professor( gynae ), Khulna Medical College, Khulna.

b. Dr Jharna Das, Assistant professor, Institute of Nuclear, Medicine and allied science, Khulna Medical College.

c. Dr Mollik Moniruzzaman, Consultant (anaesthesia); Shaheed SK Abu Naser, Specialised Hospital, Khulna.

d. Dr Citta Ranjan Bachher, Director, Shibsha clinic, Khulna. Address for Correspondence: Dr. Eti Saha, 15/2,Ahsan Ahamed road, Khulna, Bangladesh. Mobile: 01715- 292641, email: dr.etisaha@gmail.com

Received: 30 April 2014

Accepted: 17 August 2016 some precautions during laparoscopic procedure \& post operative period which can help for continuation of intrauterine pregnancy. In our clinical experience, this is an extreme rare disorder and we feel interest to report this case. A heterotopic pregnancy can result from a natural conception; it requires a high index of suspicious for early and timely diagnosis; a timely intervention can result in a successful outcome of the intrauterine fetus.

Key words: Laparoscopic surgery, Tubal pregnancy, heterotopic pregnancy.

(J Bangladesh Coll Phys Surg 2016; 34: 218-221)

pregnancy \& also intrauterine pregnancy simultaneously after spontaneous conception that was diagnosed by using two dimensional ultrasound (2DUS). In our clinical experience, this is an extremely rare disorder and we feel interest to report this case. Purposes of this case report is to review the diagnosis of a heterotopic pregnancy, management the tubal pregnancy without interruption of intrauterine pregnancy, precautions to be taken during the surgical procedure $\&$ to mention post operative care to handle this type of case.

\section{Case Report:}

A 19 years old lady, housewife, married for 3 years, with irregular menstrual cycle, seeking baby for 8 months reported to a private outpatient clinic . Her clinical diagnosis was Polycystic Ovarian Syndrome (PCOS) \& she was advised to take folic acid \& Metformin. After few days, she presented with amenorrhea for 5 weeks, followed by scanty menstruation for 7 days. She gave no history of nausea, vomiting or abdominal pain or mastalgia. On examination, she was found haemodynamically stable. After 10 days she felt nausea, her urine for pregnancy test was positive. On Transvaginal Ultrasonogram (TVS) she was diagnosed as a case of heterotopic pregnancy, both are viable about 7 weeks 2 days duration, one is intrauterine and another is in left tubal area. Opinion from another sonologist also gave the same report. After proper counseling laparoscopy was done. On laparoscopy uterus was 


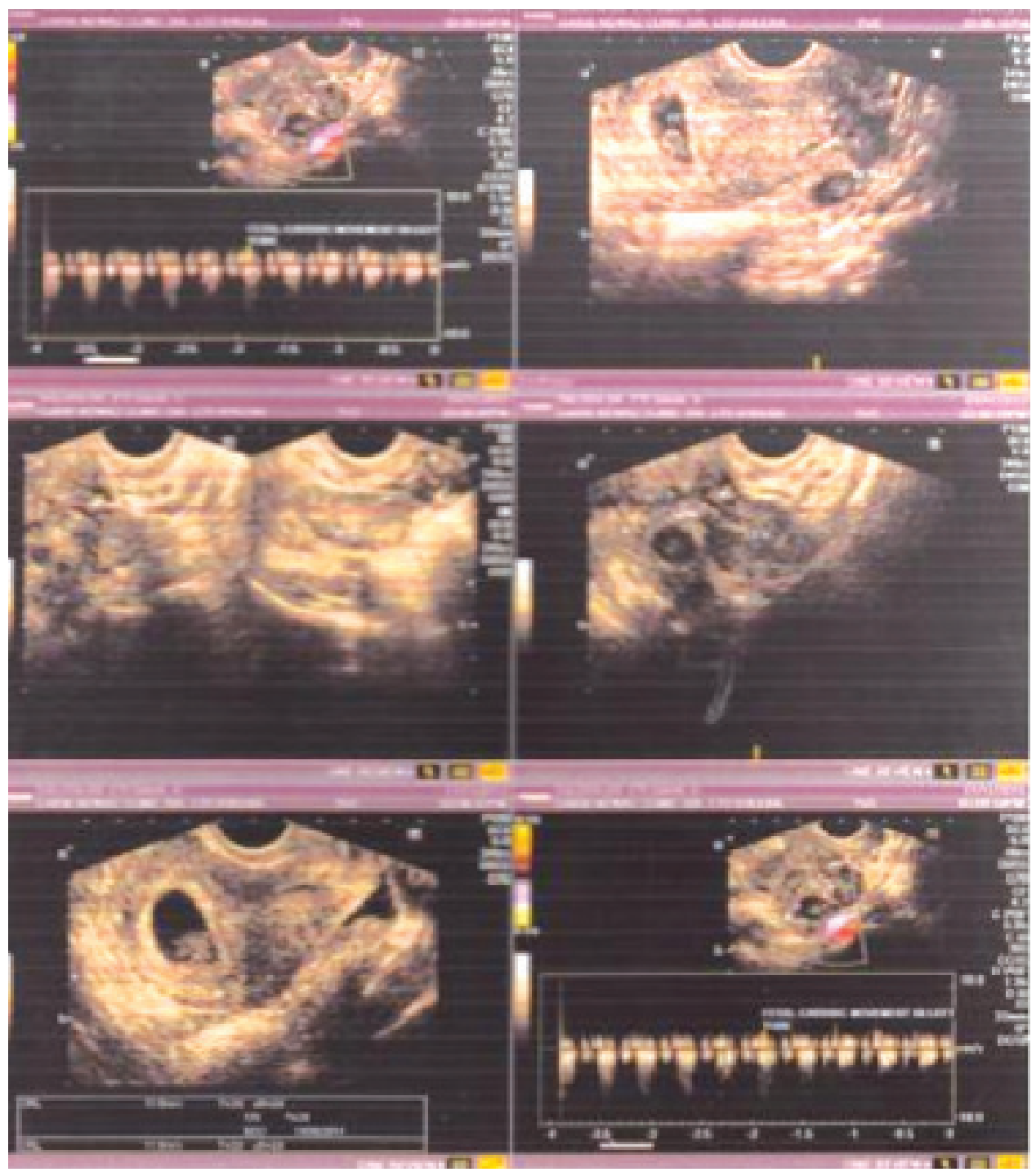

TVS report

found uniformly enlarged about 8 weeks size, right tube, both ovaries were healthy and left tube swollen and congested but not ruptured. Then left sided Salpingectomy was done without any manipulation of uterus. Post operatively her intrauterine pregnancy was supported with inj. Human Chorionic Gonadotrophin and Dydrogesterone up to 14 week. Pregnancy was continue upto term with satisfactory growth of fetus and the patient was free of any complications. Patient delivered a healthy female baby, there was no abnormality in baby.

\section{Discussions:}

Spontaneous heterotopic pregnancy is a rare clinical and potentially dangerous condition. It can be a life threatening condition and can be easily missed with the diagnosis being over looked. The importance of early diagnosis and treatment for the ectopic pregnancy becomes clear because of the high risk of tubal rupture. It is a challenge for obstetrician to manage the tubal pregnancy without interruption of intrauterine pregnancy. This case was diagnosed at 7 weeks which was intact and alive. 
The early diagnosis of heterotopic pregnancy is often difficult because the clinical symptoms are lacking. Around $50 \%$ of heterotopic pregnancies are asymptomatic. Common presenting symptoms and signs are abdominal pain, adenexal mass, peritoneal irritation, enlarged uterus, hypovolaemic shock with or without vaginal bleeding 6 .

Diagnosing this clinical occurrence is a challenge, given the complexity of the possible clinical and laboratory manifestation. The recent advances of trans vaginal sonography (TVS) helped in the early diagnosis of heterotopic pregnancy. TVS has proven to be an invaluable tool in the diagnosis of this condition. The typical image of heterotopic pregnancy on TVS are the presence of an intra uterine gestation with an ectopic tubal pregnancy contained an embryo ${ }^{7}$ or a tubal ring was present in which the tube had not ruptured, an adenexal mass with a concentric echogenic rim of tissue, a gestational sac, surrounding a hypo echoic empty centre ${ }^{8}$ or there are no conclusive adenexal findings and the diagnosis of ectopic pregnancy may be based on ultrasound features, such as "hematoperitoneum, hematosalpinx and free fluid in the peritoneum or the pelvis e.g. in the pouch of Douglas"9. The sensitivity of TVS in diagnosing heterotopic pregnancy is only $56 \%$ at 5-6 weeks ${ }^{10}$. Even with TVS, the adenexal sac can be mistaken for a hemorrhagic corpus luteum or ovarian cyst. ${ }^{1}$ If the â- ${ }^{h C G}$ levels are higher for the period of gestation with an intrauterine pregnancy, one must look for a co existent tubal pregnancy ${ }^{11}$. So role of early transvaginal sonography \& serum â- hCG level after missed periods help in early diagnosis.

The choice of surgical or medical treatment of heterotopic pregnancy depends upon the hemodynamic status of the patient and the expertise of the physician. The laparoscopic approach is technically feasible for both cases without disrupting the course of an intrauterine pregnancy. In case the ectopic pregnancy was detected early and was unruptured treatment options include expectant management with aspiration and installation of potassium chloride or prostaglandin into the gestational $\mathrm{sac}^{12}$. Systemic methotrexate or local injection of MTX cannot be used in a heterotopic pregnancy owing to its toxicity, although some authors have used instillation of a small dose $\mathrm{e}^{13}$.

There are many advantages of laparoscopy in the pregnant patient. The improved visualization in laparoscopy may reduce the risk of uterine irritability by decreasing the need for uterine manipulation . Decreased uterine irritability results in lower rates of spontaneous abortion and preterm delivery ${ }^{14}$. Regardless of the surgical approach, the use of sutures or staples rather than electrocautery or intra myometrial injection of vasopressin - minimizes the risk of diminishing blood flow to the surviving intrauterine pregnancy, particularly during cornual resection ${ }^{15}$. The ectopic component in case of rupture is always treated surgically and the intrauterine pregnancy is expected to continue normally. Exploratory laparotomy is appropriate when a ruptured ectopic pregnancy is associated with severe intra abdominal haemorrhage. There are some precautions to be taken during surgery - the patient is placed supine in a $10^{0}$ Trendelenburg position, Veress needle inserted carefully into the abdomen to avoid perforating the gravid uterus, laparoscopy should be performed without the use of an intra cervical uterine manipulator, choice of laparoscopic salpingostomy, salpingectomy or cornual resection depends on the location of the ectopic within the fallopian tube or its remnant.

\section{Conclusion:}

A heterotopic pregnancy can result from a natural conception; it requires a high index of suspicious for early and timely diagnosis; a timely intervention can result in a successful outcome of the intrauterine fetus. Ultrasonographers must methodically examine the entire pelvic region, particularly in women who have had pelvic surgery, PID or who are conceiving after a workup to fertility. Early diagnosis is the key of successful treatment and delivery.

\section{References:}

1. P. W. Callen, "Ultrasonography in obstetrics and gynecology," in Ectopic Pregnancy, D. Levine, Ed., Saunders Elsevier, Philadelphia, Pa, USA, 5th edition pp. 1020-1047.

2. Michael D. Scheiber, Marcelle I. Cedars, Case Report: Successful non-surgical management of a heterotopic abdominal pregnancy following embryo transfer with cryopreserved-thawed embryos, Hum. Reprod. (1999) 14 (5): 1375-1377. doi: 10.1093/humrep/14.5.1375

3. Bello GV, Schonolz D, Moshirpur J, et al.: Combined pregnancy: The Mount Sinai experience. Obstet Gynecol Surv 41:603 (1986).

4. H. Fernandez and A. Gervaise, "Ectopic pregnancies after infertility treatment: modern diagnosis and therapeutic 
strategy," Human Reproduction Update, vol. 10, no. 6, pp. 503-513, 2004.

5. H. M. Xiao, F. Gong, Z. H. Mao, H. Zhang, and G. X. Lu, "Analysis of 92 ectopic pregnancy patients after in vitro fertilization and embryo transfer," Journal of Central South University, 2004;31(4): 584-587.

6. Reece EA, Petrie RH, Sirmans MF, Finster M, Todd WD. Combined intrauterine and extrauterine gestations: a review. Am J Obstet Gynecol 1983;146:323-30.

7. Poujade O, Ducarme G, Luton D. Luton Cornual heterotopic pregnancy: a case report. J Med Case Reports 2009;3:7233

8. Fleischer AC, Pennell RG, McKee MS, Worrell JA, Keefe B, Herbert CM, et al. Ectopic pregnancy: features at transvaginal sonography. Radiology 1990;174:375-8.

9. Bourgon DR. Ectopic prgenancy. eMedicine. Available from: http://www.emedicine.com/radio/topic231.htm [last accessed on 2008 Jan 15]. [last cited on 2005 Dec 5].

10. Dundar O, tutuncu L, Mungen E, Muhcu M, Yergok YZ. Heterotopic pregnancy: Tubal ectopic pregnancy and monochorionic monoamniotic twin pregnancy: A case report. Perinat J 2006;14:96-100.

11. Hassani KI, El Bouazzaoui A, Khatouf M, Mazaz K. Heterotopic pregnancy: A diagnosis we should suspect more often. J Emerg Trauma Shock 2010;3:304.

12. Lialios GA, Kallitsaris A, Kabisios T, Messinis IE. Ruptured heterotopic interstitial pregnancy: rare case of acute abdomen in a Jehovah2 s witness patient. Fertil Steril 2008;90:1200.e15-7.

13. Oyawoyea S, Chander B, Pavlovic B, Hunter J, Gandir AA. Heterotopic pregnancy: successful management with aspiration of cornual/interstitial gestational sac and installation of small dose of methotrexate. Fetal Diagn Ther $2003 ; 18: 1-4$.

14. SAGES GUIDELINES 23 - Laparoscopy and Trimester of Pregnancy.

15. Sherer DM, Scibetta JJ, Sanko SR. Heterotopic quadruplet gestation with laparoscopic resection of ruptured interstitial pregnancy and subsequent successful outcome of triplets. Am J Obstet Gynecol. 1995;172(1):216-217. 